\title{
Antenatal care utilization increase the odds of women knowledge on neonatal danger sign: a community-based study, eastern Ethiopia
}

Tesfaye Assebe Yadeta*

\begin{abstract}
Objective: This study, aimed to determine women knowledge on key neonatal dander sign and associated factors among women recently gave birth in eastern Ethiopia.

Results: Of the 757 women interviewed, fever was reported as a neonatal danger sign by 255 (33.7\%) followed by poor sucking (24.8\%), difficulty breathing (23.5\%), convulsion (16.0\%), lethargy (12.9\%), a very small baby (11.8\%) and hypothermia (2.9\%). Overall 9.38\% listed four or more danger signs spontaneously. Attending at least one antenatal care visit $[A O R=2.83 ; 95 \% \mathrm{Cl}(1.62,4.93)]$, and giving birth at health facilities $[A O R=3.31 ; 95 \% \mathrm{Cl}(1.67,6.53)]$ were significantly associated with knowledge of neonatal danger signs.
\end{abstract}

Keywords: Neonatal mortality, Haramaya, District, Danger signs, East, Ethiopia

\section{Introduction}

Danger signs are signs that can be easily identified by non-clinical personnel including the mother. The four neonatal key danger sign are convulsions/spasms/rigidity, difficult/fast breathing, very small baby, and lethargy/ unconsciousness. The danger signs were selected as key because they are common, easy to recognize, and associated with a potentially severe problem [1]. Women knowledge of neonatal key danger sign is crucial to influence their decisions to seek immediate health care for their sick neonate $[2,3]$.

Women knowledge of neonatal danger signs was vary from country to country and across region. In sub Saharan Africa the level of women knowledge on neonate danger signs were low [4-7]. Factors associated with knowledge of women on neonate danger sign include women educational level, antenatal care visit, health

${ }^{*}$ Correspondence: tesfaye.assb@gmail.com

School of Nursing and Midwifery, College of Health and Medical Sciences,

Haramaya University, P.O.B. 235, Harar, Ethiopia facilities delivery, post natal care utilization, accompaniment by spouse [5-8].

In Ethiopia, neonatal mortality is still high at 25 deaths per 1000 live births. Maternal and neonatal health care seeking are among the lowest in the world, $32 \%$ of women attend 4 or more antenatal visits, $16 \%$ of women give birth by skilled birth attendant, $17 \%$ receive post-natal visits $[9,10]$. Until the 40th day of life, neonates are considered to be strangers to the community (not human). Their deaths are not talked [11].

More than $80 \%$ of all neonatal deaths are caused by preventable and treatable, if neonates seek health care [12]. Women knowledge of neonatal key danger sign is crucial to influence their decisions to seek immediate health care for their sick neonate. Failure to seek professional help may be related to lack of knowledge of neonatal danger signs [13]. Little is known about knowledge of danger sign and associated factors in the study area. Therefore, this study aims to assessing the knowledge and associated factors women on neonate danger signs. 


\section{Main text}

\section{Study design, period, and setting}

A community based cross sectional study was conducted to describe the current knowledge of women in June 2012. The study was conducted in East Hararge Zone, Oromia Region, eastern Ethiopia $507 \mathrm{~km}$ East of Addis Ababa. The district has 34 rural kebeles (neighbourhoods) and 2 urban kebeles (the smallest administrative unit in Ethiopia). Each kebeles has two health extension workers who undergo a 1 year training program and provide primary health care including basic curative and preventative services.

\section{Sample size determination, sampling recruitment and sampling procedure}

All mothers who gave birth in the last 2 years (May 2010April 2012) and resided in the district were the source population. Mothers residing in randomly selected kebeles were included in the sample. The sample was calculated using a single population proportion by taking awareness on neonatal danger signs of $50 \%, 5 \%$ margin of error, 95\% confidence level, design effect of two and 5\% non-response rate. A two-stage sampling method was used to select study subjects. In the first stage, we selected four kebeles out of the thirty-four kebeles using a simple random sampling method. Then women who gave birth in the last 2 years in the selected kebeles were identified using the health extension workers records $($ No $=1200)$. We used these records as the sampling frame to select the respondents using simple random sampling from a sample size of 806. The birth records are a complete list. Each kebele has two health extension workers (HEWs) who visit each household regularly. These HEWs know the number of pregnant women (including ANC status) in their catchment population, the number of women with children under 1 and between 2 and 5 years (including their children's immunization and nutritional status).

\section{Data collection procedure}

Data collection was undertaken using an interviewer administered structured questionnaire that was adapted from the Safe Motherhood questionnaire developed by the Maternal and Neonatal Health Program of JPHIEGO and WHO $[1,14]$. The questionnaire consisted of questions to establish women's awareness and knowledge of neonatal danger signs including convulsions or spasms or rigidity, difficult or fast breathing, very small baby, and lethargy or unconsciousness, body temperature (hypothermia, fever), and feeding (no or poor sucking). It also contained questions to gather socio-demographic data such as age, educational status, occupation status, family size; reproductive health characteristics such as gravidity, parity and antenatal follow up and health care practice. The questionnaire was prepared in English, translated to Afan Oromo and then back translated by language expertise. The questionnaire was pretested on 42 women from another district and modified accordingly. Data was collected by nurse/midwifery who had research field work experience. We provided a 2-day training course for the data collectors and supervisors. The completeness and consistency of data daily checked at the site of data collection by supervisor.

\section{Measurement}

A knowledge score for neonatal danger signs was computed using the neonate danger signs spontaneously listed by the mothers. These signs were selected because they strongly predict neonatal mortality [1] are considered danger signs as per the conceptual framework described above [14]. All correct responses were assigned a value of 1 while 0 was given for wrong answers. All women who spontaneously mentioned the four and above danger signs were considered knowledgeable.

\section{Data processing and analysis}

The data were entered and cleaned using EpiData version 3.1 and analysed using STATA software version 13. First descriptive statistics were computed to describe individual variables using frequencies and percentages. Binary logistic regression was fitted to assess the association between knowledge of danger signs and individual independent variables. Variables with $\mathrm{p}$-value $\leq 0.2$ in the bivariable analyses were considered in the multivariable logistic regression model. Adjusted odds ratio (AOR) along with 95\% confidence interval was estimated to assess the strength of the association, and a p-value $\leq 0.05$ was used to declare the level of statistical significance.

\section{Results \\ Socio-demographic and maternal health characteristics of respondents}

A total of 757 (a response rate of 94\%) women were interviewed with the mean age of $26.34 \pm 6.62$ years. Most women were Muslim (97.5\%), belonged to the Oromo ethnic group (95.6\%) and married (93.3\%). About three in four of the women were rural residents (74\%) and illiterate $(72.7 \%)$. In terms of pregnancy, $29.7 \%$ of the women reported having been pregnant five times or more and $14 \%$ of the women reported experiencing abortion. A total of 323 (42.67\%) women stated that they had attended at least once antenatal care (ANC) visits during their last pregnancy, of which $77(23.83 \%)$ reported attending all the recommended four visits. Most women $(86.8 \%)$ stated that they had given birth to their last baby 
at home and majority of the deliveries (95.8\%) were normal vaginal births without complications (Table 1).

\section{Knowledge of neonatal danger signs}

In terms of the respondent's knowledge the women interviewed noted awareness of seven neonatal danger signs. The most listed danger sign was fever (33.7\%), followed by poor sucking of the neonate (24.8\%). Overall $9.38 \%$ listed four or more danger signs spontaneously (Fig. 1).

\section{Factors associated with knowledge of danger signs}

The multivariable logistic regression analysis revealed antenatal follow up $[\mathrm{AOR}=2.83 ; 95 \% \mathrm{CI}(1.62,4.93)]$ and

Table 1 Socio-demographic characteristics of women by their knowledge in Haramaya district, eastern Ethiopia, $2012(n=757)$

\begin{tabular}{|c|c|c|c|}
\hline \multirow[t]{2}{*}{ Character } & \multirow[t]{2}{*}{ Total } & \multicolumn{2}{|c|}{ Neonatal knowledge } \\
\hline & & Knowledgeable & Non-knowledgeable \\
\hline \multicolumn{4}{|c|}{ Age of women in year } \\
\hline$\leq 25$ & $534(70.54 \%)$ & $53(9.93)$ & $481(90.07)$ \\
\hline$>25$ & $223(29.46 \%)$ & $18(8.07)$ & 205 (91.93) \\
\hline \multicolumn{4}{|l|}{ Residence } \\
\hline Urban & $197(26.02 \%)$ & $17(8.63)$ & $180(91.37)$ \\
\hline Rural & $560(73.98 \%)$ & $54(9.64)$ & $506(90.36)$ \\
\hline \multicolumn{4}{|c|}{ Ethnic group } \\
\hline Oromo & $724(95.64 \%)$ & $69(9.53)$ & $655(90.47)$ \\
\hline Others & $33(4.36 \%)$ & $2(6.06)$ & $31(93.94)$ \\
\hline \multicolumn{4}{|c|}{ Educational status } \\
\hline Literate & $207(27.34 \%)$ & $26(12.56)$ & $181(87.44)$ \\
\hline Illiterate & $550(72.66 \%)$ & $45(8.18)$ & $505(91.82)$ \\
\hline \multicolumn{4}{|l|}{ Occupation } \\
\hline House wife & $453(59.84 \%)$ & $47(10.38)$ & $406(89.62)$ \\
\hline Others & $304(40.16 \%)$ & $24(7.89)$ & $280(92.11)$ \\
\hline \multicolumn{4}{|c|}{ Marital status } \\
\hline Married & 706 (93.26\%) & $64(9.07)$ & $642(90.93)$ \\
\hline Others & $51(6.74 \%)$ & $7(13.73)$ & $44(86.27)$ \\
\hline \multicolumn{4}{|c|}{ Number of delivery } \\
\hline $1-2$ & 291 (38.44\%) & $18(6.19)$ & $273(93.81)$ \\
\hline $3-4$ & $307(40.55 \%)$ & $32(10.42)$ & $275(89.58)$ \\
\hline$\geq 5$ & $159(21.01 \%)$ & $21(13.21)$ & $138(86.79)$ \\
\hline \multicolumn{4}{|c|}{ History of abortion } \\
\hline Yes & $106(14.00 \%)$ & $10(9.43)$ & $96(90.57)$ \\
\hline No & $651(86.00 \%)$ & $61(9.37)$ & $590(90.63)$ \\
\hline \multicolumn{4}{|c|}{ Pace of delivery } \\
\hline Home & $657(86.79 \%)$ & $48(7.31)$ & 609 (92.69) \\
\hline Institution & $100(13.21 \%)$ & $23(23.00)$ & $77(77.00)$ \\
\hline \multicolumn{4}{|c|}{ ANC follow up } \\
\hline Yes & $323(42.67 \%)$ & $49(15.17)$ & $274(84.83)$ \\
\hline No & $434(57.33 \%)$ & $22(5.07)$ & $412(94.93)$ \\
\hline
\end{tabular}

had no given birth in a health facility $[\mathrm{AOR}=3.31 ; 95 \%$ CI $(1.67,6.53)]$ were significantly associated with maternal knowledge of neonate danger signs (Table 2).

\section{Discussion}

In this study, women knowledge of neonatal danger signs was $9.38 \%$. Factors that significantly associated to women knowledge of neonatal danger signs were Women with at least one ANC follow up and giving birth at health facilities.

This study found that, only $9.38 \%$ of the women interviewed knew four or more neonatal danger signs. Women's knowledge of neonatal danger signs varies in sub Saharan Africa. In Uganda only $14.8 \%$ could name at least two danger signs [5]. In Nigeria, the percentage of mothers who were able to recognize four or more neonatal danger signs was $30.3 \%$ [15]. In Kenya $15.5 \%$ of mothers identified four or more neonatal danger signs [16]. Women knowledge of neonatal danger sign was variable, the reason may be due to difference in socio-demographic, economic, health care utilization and women educational status [17].

Women knowledge of neonatal key danger sign is crucial to influence their decisions to seek immediate health care for their sick neonate. Failure to seek professional help may be related to lack of knowledge of neonatal danger signs [2]. To achieve sustainable development goal of their neonatal mortality reduction program planner and health facilities found in the country need to include information dissemination of neonatal danger into their maternal and neonatal health care strategies.

In this study, we found that mothers who visited of at least one ANC follow up and give birth at health facility were significantly associated with, knowledge of neonatal danger sign which is consistent with the findings of studies conducted elsewhere [5]. Counselling of mother on

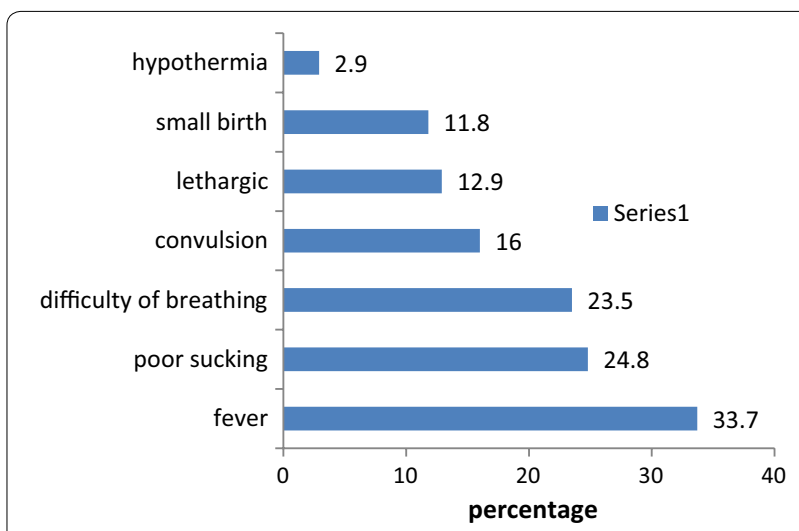

Fig. 1 Knowledge of neonatal danger signs among women who recently gave birth in Haramaya District, eastern Ethiopia, 2012 
Table 2 Predictors of good knowledge about neonatal danger signs among women in Haramaya district, eastern Ethiopia, 2012

\begin{tabular}{|c|c|c|c|c|}
\hline \multirow[t]{2}{*}{ Character } & \multicolumn{2}{|c|}{ Crudes OR } & \multicolumn{2}{|c|}{ Adjusted OR } \\
\hline & OR & $95 \% \mathrm{Cl}$ & OR & $95 \% \mathrm{Cl}$ \\
\hline \multicolumn{5}{|c|}{ Age of women in year } \\
\hline$\leq 25$ & 1.25 & $0.71,2.19$ & 1.75 & $0.92,3.32$ \\
\hline$>25$ & 1 & & 1 & \\
\hline \multicolumn{5}{|l|}{ Residence } \\
\hline Urban & 1.12 & $0.63,2.00$ & 2.36 & $0.51,10.79$ \\
\hline Rural & 1 & & 1 & \\
\hline \multicolumn{5}{|c|}{ Educational status } \\
\hline Literate & 1 & & 1 & \\
\hline Illiterate & 0.62 & $0.37,1.03$ & 0.99 & $0.50,1.97$ \\
\hline \multicolumn{5}{|l|}{ Occupation } \\
\hline House wife & 1 & & 1 & \\
\hline Others & 1.35 & $0.80,2.25$ & 1.56 & $0.86,2.81$ \\
\hline \multicolumn{5}{|l|}{ Marital status } \\
\hline Married & 1 & & 1 & \\
\hline Others & 0.62 & $0.27,1.44$ & 0.59 & $0.20,1.74$ \\
\hline \multicolumn{5}{|c|}{ History of abortion } \\
\hline Yes & 1 & & 1 & \\
\hline No & 0.99 & $0.49,2.00$ & 1.30 & $0.52,3.20$ \\
\hline \multicolumn{5}{|c|}{ ANC follow up } \\
\hline No & 1 & & 1 & \\
\hline Yes & 3.34 & $1.97,5.66^{* * *}$ & 2.83 & $1.62,4.93^{* * *}$ \\
\hline \multicolumn{5}{|c|}{ Pace of delivery } \\
\hline Home & 1 & & 1 & \\
\hline Institution & 3.78 & $2.18,6.57^{* * *}$ & 3.31 & $1.67,6.53^{* *}$ \\
\hline
\end{tabular}

ANC antenatal care; $O R$ odds ratio

${ }^{* * *}$ significant at $\mathrm{p}<0.001 ;{ }^{* *}$ significant at $\mathrm{p}<0.05$

neonatal danger sign during ANC, delivery and PNC is one component of health care. However, ANC follow up and health facilities delivery was very low. In this study only $19.0 \%$ pregnant women for 4 visits while the proportion of women giving birth at health facilities were $10 \%$. Urgent effective intervention is needed to improve the coverage of ANC follow up and health facilities delivery in their maternal and neonatal reduction strategy [18].

The low utilization of health services together with low awareness of neonatal danger signs is problematic and highlights the need for major action to generate demand for health services and improve community knowledge to reduce neonatal death. The results of this study can inform current initiatives that are focused on improving maternal and newborn health care delivery in rural Ethiopia. The findings of our study serve to further emphasise the important role that HEWs must continue to play in relaying information about neonatal danger signs, as well as working to actively engage community members to encourage women and their families to seek help [19].

Community involvement in health care has been found to be a cost-effective strategy to improve maternal and neonatal survival in low-resource settings [20]. However, empowering communities to participate in health care is dependent on the capacity of that community to make decisions and the socio-cultural and health system context.

Several health promotion strategies could be used to strength efforts at community level to improve community recognition of neonatal danger signs and helpseeking behaviours. Innovative approaches noted in the literature include a mobile video show designed to improve community knowledge, attitudes, and beliefs regarding maternal and newborn health, especially careseeking behaviour and the use of a skilled birth attendant and postnatal care [2]. Mobile health (m Health) applications such as the use of mobile phones and and tablet computers also show promise [21].

Despite the possibilities shown by such strategies, alongside improved service delivery and health worker training, further efforts will be required. Community capacity building and socio-cultural change is also needed to transform Ethiopian community attitudes and behaviours, as well as a national vital registration system to provide intelligence for health service planning. Scaling up evidence-based and novel approaches and coordinating these is essential to accelerate an increase in women's awareness of the signs and symptoms of newborn illness and mobilise communities to seek medical assistance to reduce preventable neonatal death.

\section{Conclusions}

Mother's knowledge of neonatal danger signs appears to be low. These findings reveal an urgent need to increase women awareness of neonatal danger signs. Effort is needed to access pregnant women to antenatal care and health facilities delivery services help the women to improve their awareness.

\section{Limitations of the study}

The use of a cross sectional design in this study did not allow for causal relationships to be established, thus the reasons why women reported certain danger signs more so than others is not known. In addition, the study assessed the knowledge of woman who gave birth in the last 2 years. Findings may therefore be affected by recall bias and the failure the woman to differentiate between the neonatal and post neonatal period. Limiting interviews to mothers who had given birth within the last 28 days might have rendered more accurate data. Furthermore, the influence of women knowledge on health 
seeking behaviour was not assessed using theoretical model, which help health care provider for intervention. In addition, unaccounted and residual confounding could have an effect on the association.

\section{Abbreviations}

ANC: antenatal care; HEW: health extension workers; MaNHEP: the maternal and newborn health in Ethiopia partnership; NMR: neonatal mortality rate; WHO: World Health Organization.

\section{Authors' contributions}

TA developed the proposal, collected data and reviewed and analysed the data, prepared the manuscript, revised subsequent drafts. The author read and approved the final manuscript.

\author{
Acknowledgements \\ I also would like to thank all the women who willingly participated in this \\ study.
}

\section{Competing interests}

The author declares that I have no competing interests. Haramaya University had no role in the design, data collection, analysis or decision to publish the paper.

\section{Availability of data and materials}

The datasets used and/or analysed during the current study are available from the corresponding author on reasonable request.

\section{Consent for publication}

Not applicable.

\section{Ethics approval and consent to participate}

The study was reviewed and approved by the Institutional Health Research Ethics Review Committee of the Colleges of Health and Medical Sciences, Haramaya University. Written consent was obtained from each woman before commencement of data collection. Participants under the age of 18 provide their assent in addition to written consent of their parent or legal guardians. To maintain confidentiality, interviews and specimen collection were conducted in a separate room and all information obtained in this study was handled with anonymity.

\section{Funding}

Haramaya University financially supported the study. The funders had no role in study design, data collection and analysis, decision to publish, or preparation of the manuscript.

\section{Publisher's Note}

Springer Nature remains neutral with regard to jurisdictional claims in published maps and institutional affiliations.

Received: 10 October 2018 Accepted: 26 November 2018 Published online: 29 November 2018

\section{References}

1. Del Barco R. Monitoring birth preparedness and complication readiness. In: Tools and indicators for maternal and newborn health. 2004.

2. Sibley LM, Tesfaye S, Fekadu Desta B, Hailemichael Frew A, Kebede A, Mohammed H, Ethier-Stover K, Dynes M, Barry D, Hepburn K. Improving maternal and newborn health care delivery in rural Amhara and Oromiya regions of Ethiopia through the Maternal and Newborn Health in Ethiopia Partnership. J Midw Womens Health. 2014;59:s1.

3. Noordam AC, Sharkey AB, Hinssen P, Dinant G, Cals JW. Association between caregivers' knowledge and care seeking behaviour for children with symptoms of pneumonia in six sub-Saharan African Countries. BMC Health Serv Res. 2017;17(1):107.

4. Alex-Hart B, Dotimi D, Opara P. Mothers' recognition of newborn danger signs and health seeking behaviour. Niger J Paediatr. 2014;41(3):199-203.

5. Sandberg J, Pettersson KO, Asp G, Kabakyenga J, Agardh A. Inadequate knowledge of neonatal danger signs among recently delivered women in southwestern rural Uganda: a community survey. PLoS ONE. 2014;9(5):e97253.

6. Kanu JS, Tang Y, Liu Y. Assessment on the knowledge and reported practices of women on maternal and child health in rural Sierra Leone: a cross-sectional survey. PLoS ONE. 2014:9(8):e105936.

7. Nigatu SG, Worku AG, Dadi AF. Level of mother's knowledge about neonatal danger signs and associated factors in North West of Ethiopia: a community based study. BMC Res Notes. 2015;8(1):309.

8. Saaka M, Iddrisu M. Patterns and determinants of essential newborn care practices in rural areas of northern Ghana. Int J Popul Res. 2014;2014:10.

9. Debelew GT, Afework MF, Yalew AW. Determinants and causes of neonatal mortality in Jimma zone, southwest Ethiopia: a multilevel analysis of prospective follow up study. PLOS ONE. 2014;9(9):e107184.

10. Central Statistical Agency (CSA) [Ethiopia] and ICF. Ethioia demographic and health survey: key indicator report. Addis Ababa: CSA and ICF; 2016

11. Sisay MM, Yirgu R, Gobezayehu AG, Sibley LM. A qualitative study of attitudes and values surrounding stillbirth and neonatal mortality among grandmothers, mothers, and unmarried girls in rural Amhara and Oromiya regions, Ethiopia: unheard souls in the backyard. J Midw Womens Health. 2014:59(s1):S110-7.

12. Oza S, Lawn JE, Hogan DR, Mathers C, Cousens S. Cause-of-death estimates for the early and late neonatal periods for 194 countries from 2000 to 2013. 2014. arXiv preprint arXiv:14114021.

13. Herbert HK, Lee ACC, Chandran A, Rudan I, Baqui AH. Care seeking for neonatal illness in low- and middle-income countries: a systematic review. PLoS Med. 2012;9(3):e1001183.

14. WHO U. Caring for the newborn at home; a training course for community health workers; community health workers manual. Geneva: WHO; 2012

15. Ekwochi U, Ndu IK, Osuorah CD, Amadi OF, Okeke IB, Obuoha E, Onah KS, Nwokoye I, Odetunde Ol, Obumneme-Anyim NI. Knowledge of danger signs in newborns and health seeking practices of mothers and care givers in Enugu state, South-East Nigeria. Ital J Pediatr. 2015;41(1):18.

16. Kibaru EG, Otara AM. Knowledge of neonatal danger signs among mothers attending well baby clinic in Nakuru Central District, Kenya: cross sectional descriptive study. BMC Res Notes. 2016;9(1):481.

17. Yadeta TA, Kumsa FA. Awareness and health care practice of mothers' about obstetric danger signs at Haramaya District, eastern Ethiopia. J Fam Med Health Care. 2017;3(1):23-9.

18. Yadeta TA, Worku A, Egata G, Seyoum B, Marami D, Berhane Y. Vertical transmission of group B Streptococcus and associated factors among pregnant women: a cross-sectional study, eastern Ethiopia. Infect Drug Resist. 2018;11:397.

19. Banteyerga H, Kidanu A. A rapid appraisal of health extension program: Ethiopia country report. Addis Ababa: The L10K project and MHRC; 2008.

20. Prost A, Colbourn T, Seward N, Azad K, Coomarasamy A, Copas A, Houweling TA, Fottrell E, Kuddus A, Lewycka S. Women's groups practising participatory learning and action to improve maternal and newborn health in low-resource settings: a systematic review and meta-analysis. Lancet. 2013;381(9879):1736-46.

21. UNICEF. Maternal and perinatal death inquiry and response: Empowering communities to avert maternal deaths in India. Geneva: UNICEF; 2005. 